\title{
HUBUNGAN JENIS KELAMIN, OLAH RAGA DAN OBESITAS DENGAN KEJADIAN DIABETES MELLITUS PADA LANSIA
}

\author{
Nova Rita ${ }^{1}$ \\ ${ }^{1}$ AKPER ‘AISYIYAH Padang, Jl. Gajah Mada, Komplek Kesehatan, Gn. Pangilun, Kota Padang, \\ Indonesia 25173 \\ Email: nova_rita07@yahoo.com
}

\begin{abstract}
ABSTRAK
Kejadian diabetes mellitus di Indonesia 7,6 juta jiwa penderita diabetes mellitus, Sumatera Barat urutan ke 3 yaitu 1,5\% dan 0,4\%. dari survei awal pada RW 1X dan X Kelurahan Surau Gadang didapatkan 8 dari 10 lansia menderita diabetes mellitus. Penelitian bertujuan untuk mengetahui faktor - faktor yang berhubungan dengan kejadian diabetes mellitus pada lansia. Jenis penelitian analitik dengan pendekatan cross sectional. Penelitian di Posyandu Lansia RW 1X dan X Kelurahan Surau Gadang bulan Mei sampai Agustus 2015. Pengumpulan data tanggal 30 Juli sampai 06 Agustus 2015. Populasi berjumlah 78 lansia dan teknik pengambilan sampel total sampling. Penelitian menggunakan kuesioner dengan cara wawancara. Pengolahan data dilakukan dengan komputerisasi. Analisa data digunakan yaitu analisis univariat dan bivariat. Hasil penelitian menunjukkan bahwa $(57,7 \%)$ lansia mengalami diabetes mellitus, $(59 \%)$ jenis kelamin perempuan, $(62,8 \%)$ tidak ada olahraga, dan $(65,4 \%)$ tidak obesitas. Uji Chi-Square disimpulkan terdapat hubungan jenis kelamin $(\mathrm{p}=0,000)$ olahraga $(\mathrm{p}=0,000)$ dan obesitas $(\mathrm{p}=0,000)$ dengan kejadian diabetes mellitus. Diharapkan dapat menjadi masukan bagi kader - kader kesehatan mengenai pentingnya faktor- faktor yang berhubungan dengan kejadian diabetes mellitus pada lansia. Pencegahan diabetes mellitus dapat dilakukan dengan meningkatkan pengetahuan lansia dengan memberikan penyuluhan dan memperbaiki pola makan.
\end{abstract}

Kata Kunci : Diabetes mellitus, jenis kelamin, olahraga, obesitas.

\begin{abstract}
The incidence of diabetes mellitus in Indonesia is about 7,6 million diabetics. West Sumatera, the third rank is about 1,5\% and 0,4\% . from the preliminary at $R W I X$ and $X$ surau gadang, it got 8 out of 10 elderly suffered diabetes mellitus. This research aims to know the related factors with diabetes mellitus incidents on elderly. The type of this research is descriptive analytic with cross sectional approach. This Research was conducted may to august at the Posyandu Elderly RW $1 x$ and X Surau, Gadang .The data was collected on 30 July to 3 August 2015. The Populations are 78 elderly. The samle was taken by total sampling technique. The Research used the questionnaire/ interviews. The data was proceed by computerization. The data was analyzed by using univariate analysis and bivariate. The research showed,(57,7\%) the elderly suffers diabetes mellitus, (59\%) women, (62,8\%)don't do exercise, and (65,4\%)aren't obese the Chi-Square test concluded that there is correlation significance between sex $(p=0,000)$ exercise $(p=0,000)$ and obesity $(p=0,000)$ with the incident of diabetes mellitus. It's expected to be a suggestion for the leaders of health about the importance of the related factors with incidents of diabetes mellitus on elderly. Prevention of diabetes mellitus can be done by increasing the knowledge of the elderly by providing counseling and improve diet .
\end{abstract}

Keywords: Diabetes mellitus, sex, exercise, obesity 


\section{PENDAHULUAN}

Diabetes mellitus merupakan keadaan hiperglikemia kronik disertai berbagai kelainan metabolik akibat gangguan hormonal yang menimbulkan komplikasi pada mata, ginjal, saraf, dan pembuluh darah (Nugroho, 2011). Diabetes mellitus merupakan penyakit keturunan yang sulit disembuhkan. Dari tahun ketahun penderita diabetes mellitus di Indonesia semakin bertambah, bahkan penyakit diabetes mellitus membunuh lebih banyak dibandingkan dengan penyakit HIV (Mansjoer, 2010). Faktor - faktor yang berhubungan dengan kejadian diabetes mellitus adalah pola makan, obesitas, faktor genetik, bahan-bahan kimia, pola hidup atau kebiasaan olahraga, kehamilan gestasional, penyakit atau infeksi pankreas, dan bahan beracun (Hasdianah, 2012).

Menurut Trisyanisya (2012) dalam Utami (2013) jumlah penderita diabetes mellitus secara global terus meningkat setiap tahunnya. Menurut World Health Organization (WHO), diabetes mellitus menempati peringkat ke-6 sebagai penyebab kematian. International Diabetes Federation (IDF) memperhitungkan angka kejadian diabetes mellitus didunia pada tahun 2012 adalah 371 juta jiwa, tahun 2013 meningkat menjadi 382 juta jiwa dan diperkirakan pada tahun 2035 diabetes mellitus akan meningkat menjadi 592 juta jiwa. Angka kejadian diabetes mellitus di Indonesia termasuk urutan terbesar ke 7 dunia yaitu sebesar 7,6 juta jiwa dan diprediksi akan meningkat pada tahun 2030 menjadi 21,3 juta orang.

Menurut Riset Kesehatan Dasar Nasional (Riskesdas) menunjukan prevalensi penderita diabetes mellitus di Indonesia tahun 2007$2013(1,1 \%-2,1 \%)$. Sedangkan di Sumatera Barat tahun 2007-2013 (1,1\% - 1,8\%) dan Sumatera Barat menempati urutan ke 3 terbesar dalam jumlah diabetes mellitus yaitu 1,5\% dan 0,4\% (Riskesdas, 2013).

Berdasarkan data dari Dinas Kesehatan Kota Padang tahun 2013 lansia yang menderita diabetes mellitus berjumlah 1539 orang yang datang dan berobat ke Puskesmas dari total keseluruhan Puskesmas yang ada di kota Padang. Lansia yang menderita diabetes mellitus dari 22 Puskesmas yang ada di kota Padang, pada tahun 2013 Puskesmas Nanggalo yang tertinggi yaitu sebanyak 414 orang (DKK Padang, 2013).

Berdasarkan data kunjungan dari bulan Januari - Desember 2014 didapatkan data lansia yang menderita diabetes mellitus adalah sebanyak 698. Wilayah Kerja Puskesmas memiliki 24 Posyandu lansia dan 17 Posyandu lansia yang aktif, dari 17 posyandu yang aktif terdapat 2 posyandu yang tertinggi diabetes mellitus pada lansia yaitu di RW IX dan RW X Kelurahan Surau Gadang, didapatkan data dari posyandu Lansia RW IX dan X jumlah Lansia sebanyak 78 orang.

Berdasarkan survei awal yang dilakukan di RW IX dan RW X pada tanggal 01 Juni 2015 dengan wawancara kepada 10 orang lansia, didapatkan 8 orang lansia yang menderita penyakit diabetes mellitus, dari 8 orang lansia yang menderita diabetes mellitus tersebut didapatkan 7 orang lansia berjenis kelamin perempuan. 8 orang lansia menyatakan menderita penyakit diabetes melitus disebabkan ada anggota keluarganya yang menderita diabetes mellitus.

Dari 8 lansia yang menderita diabetes mellitus 5 orang lansia mengatakan karena pola hidupnya yang kurang berolahraga seperti senam lansia, jalan kaki santai, didapatkan 4 orang lansia mengatakan pernah mengalami obesitas sebelum mengetahui sakitnya dan setelah menderita diabetes mellitus lansia mengalami penurunan berat badan selanjutnya 1 orang lansia mengatakan mengalami diabetes karena hipertensi.

Berdasarkan permasalahan di atas peneliti telah melakukan penelitian tentang "Hubungan jenis kelamin, olah raga dan obesitas dengan Kejadian Diabetes Mellitus Pada Lansia di Posyandu Lansia RW IX dan RW X Kelurahan Surau Gadang di Wilayah Kerja Puskesmas Nanggalo Padang Tahun 2015".

\section{METODE PENELITIAN}

Pada penelitian ini mengunakan desain penelitian analitik kemudian datanya dianalisis hubungan antar variabel. Lokasi penelitian di Posyandu Lansia RW IX dan RW X Kelurahan Surau Gadang di wilayah kerja Puskesmas Nanggalo Padang. Waktu Pelaksanaan penelitian ini dilaksanakan mulai bulan Mei sampai Agustus 2015. 
Populasi dalam penelitian ini adalah semua lansia di Posyandu Lansia RW IX dan RW X Kelurahan Surau Gadang di Wilayah Kerja Puskesmas Nanggalo Padang dengan jumlah lansia sebanyak 78 orang dan subyek penelitian sebanyak 78. Dalam penelitian yang dilakukan menggunakan uji valitas terhadap 30 responden ditempat yang berbeda dengan tempat penelitian.

\section{III.HASIL PENELITIAN}

Hasil penelitian ini menjelaskan tentang analisa univariat dan bivariat pada variabel dependen kejadian Diabetes Mellitus dan variabel independen ; 1) jenis kelamin 2) olah raga 3)obisitas dengan penjabaran sebagai berikut :

Tabel 1.1

Hubungan jenis kelamin, olah raga dan obesitas dengan kejadian Diabetes mellitus pada lansia

\begin{tabular}{|c|c|c|c|c|}
\hline \multirow[t]{2}{*}{$\begin{array}{l}\mathbf{N} \\
\mathbf{0}\end{array}$} & \multirow[t]{2}{*}{ Variabel } & \multirow[t]{2}{*}{ Katagori } & \multicolumn{2}{|c|}{$\begin{array}{c}\text { Kejadian Diabetes } \\
\text { Mellitus }\end{array}$} \\
\hline & & & Ya & Tidak \\
\hline \multirow[t]{2}{*}{1} & \multirow{2}{*}{$\begin{array}{c}\text { Jenis } \\
\text { kelamin } \\
(\mathbf{P}= \\
\mathbf{0 , 0 0 0})\end{array}$} & Laki-laki & $\begin{array}{c}\mathbf{8} \\
(25 \% \%)\end{array}$ & $\begin{array}{c}24 \\
(75 \%)\end{array}$ \\
\hline & & Perempuan & $\begin{array}{c}37 \\
(80,4 \%)\end{array}$ & $\begin{array}{c}9 \\
(19,6 \%)\end{array}$ \\
\hline \multirow[t]{2}{*}{2} & \multirow{2}{*}{$\begin{array}{c}\text { Olah } \\
\text { raga } \\
(\mathbf{P}= \\
\mathbf{0 , 0 0 0})\end{array}$} & Tidak Ada & $\begin{array}{c}41 \\
(83,7 \%)\end{array}$ & $\begin{array}{c}\mathbf{8} \\
(16,3 \%)\end{array}$ \\
\hline & & Ada & $\begin{array}{c}\mathbf{4} \\
(13,8 \%)\end{array}$ & $\begin{array}{c}\mathbf{2 5} \\
(86,2 \%\end{array}$ \\
\hline \multirow[t]{2}{*}{3} & \multirow[t]{2}{*}{ Obesitas } & Obesitas & $\begin{array}{c}24 \\
(88,9 \%)\end{array}$ & $\begin{array}{c}3 \\
(11,1 \%)\end{array}$ \\
\hline & & $\begin{array}{c}\text { Tidak } \\
\text { Obesitas }\end{array}$ & $\begin{array}{c}21 \\
(41,2 \%)\end{array}$ & $\begin{array}{c}30 \\
(58,8 \% \\
\end{array}$ \\
\hline
\end{tabular}

Pada tabel 1.1 dapat dilihat bahwa Pola makan yang lebih dominan beresiko terjadi Diabetes mellitus. Hasil uji chi-squre dengan batas kemaknaan dipakai $\alpha=0,05$ dan derajat kepercayaan $95 \%$ didapatkan bahwa jenis kelamin, olah raga dan obesitas maka mempengaruhi kejadian Diabetes Mellitus

\section{PEMBAHASAN}

\section{Kejadian Diabetes Mellitus pada Lansia di Posyandu Lansia}

Berdasarkan hasil penelitian yang dilakukan peneliti kepada lansia didapatkan 45 lansia $(57,7 \%)$ yang menderita diabetes mellitus dan sebanyak 33 orang yang tidak menderita diabetes mellitus. Hasil penelitian menunjukkan bahwa lebih dari separuh lansia yang mengalami kejadian diabetes melitus di Wilayah Kerja Puskesmas Nanggalo Padang tahun 2015

Hasil penelitian ini didukung oleh hasil penelitian yang dilakukan oleh Ginting, dkk (2013) tentang hubungan yang bermakna antara obesitas, keturunan, olahraga dengan kejadian diabetes mellitus di Poliklinik Penyakit dalam RSUP. H. Adam. Malik Medan Tahun 2013. Didapatkan Hasil penelitian 52\% responden menderita diabetes mellitus.

Diabetes melitus merupakan salah satu penyakit kronis yang dapat meningkatkan dengan cepat prevalensi komplikasi kronis pada lansia. Hal ini disebabkan kondisi hiperglikemia akibat ketiadaan absolut insulin atau penurunan relatif sensitivitas sel terhadap insulin, akan memicu munculnya penyakit tidak menular kronis lainnya, bahkan kematian penyandang diabetes melitus tidak jarang disebabkan oleh komplikasi. Klub Persadia Rumah Sakit Islam Jakarta Pondok Kopi Tahun 1998 - 2005 menjelaskan bahwa komplikasi diabetes terbanyak adalah hipertensi dengan proporsi sekitar 54,2\%.

Menurut analisa peneliti berdasarkan hasil penelitian yang dilakuakan tingginya angka kejadian diabtetes mellitus pada lansia di posyandu lansia RW 1X dan X Kelurahan Surau Gadang . Lansia yang mengalami diabetes mellitus disebabkan karena ketidaktahuan lansia tentang faktor penyebab diabetes mellitus. Lansia sering mengeluh haus, banyak makan, banyak minum dan juga merasa cepat lelah serta terjadinya penurunan berat badan pada lansia dan terjadinya peningkatan kadar glukosa darah.

\section{Jenis Kelamin Pada Lansia di Posyandu Lansia}

Berdasarkan hasil penelitian didapatkan 46 lansia berjenis kelamin perempuan dan 32 berjenis kelamin laki - laki. Hasil penelitian menunjukkan bahwa lebih dari separoh (59\%) lansia memiliki jenis kelamin perempuan di RW 1X dan X Kelurahan Surau Gadang Wilayah Kerja Puskesmas Nanggalo Padang tahun 2015.

Penelitian ini didukung oleh hasil penelitian yang dilakukan oleh Hartani (2014) 
di Wilayah Kerja Puskesmas Mataram, menemukan bahwa $62,8 \%$ responden memiliki jenis kelamin perempuan. Jenis kelamin adalah perbedaan seks yang didapat sejak lahir yang dibedakan antara laki-laki dan perempuan. Baik pria maupun wanita memiliki resiko terjadinya diabetes mellitus. Perempuan memiliki resiko lebih besar untuk menderita Diabetes Mellitus, daripada laki-laki, karena secara fisik wanita memiliki peluang peningkatan indeks masa tubuh yang lebih besar sindroma siklus bulanan (premenstrual syindrome). Pasca monoupouse yang membuat distribusi lemak tubuh menjadi mudah terakumulasi akibat proses hormonal tersebut sehingga wanita beresiko menderita diabetes mellitus (Wahyuni, 2014).

Menurut analisa peneliti lansia perempuan lebih banyak ditemukan daripada laki-laki di RW 1X dan X Kelurahan Surau Gadang. Salah satu faktor penyebab diabetes mellitus adalah jenis kelamin. Perempuan memiliki peluang besar menderita diabetetes mellitus dibandingkan laki-laki karena gaya hidup perempuan banyak yang tidak sehat dibanding laki-laki. lansia perempuan lebih banyak yang tidak bekerja dibandingkan lakilaki, pada perempuan lansia juga sudah terjadi pasca monoupouse yang mengakibatkan lemak tubuh menjadi mudah terakumulasi akibat proses hormonal. diharapkan kepada lansia perempuan agar lebih menjaga pola hidupnya yang sehat sehingga terhindar dari diabetes mellitus dan mengindari faktor lingkungan seperti pola hidup yang jelek, dan stress.

\section{Olahraga Pada Lansia di Posyandu Lansia}

Berdasarkan hasil penelitian didapatkan bahwa 49 lansia yang tidak ada melakukan olahraga dan 29 lansia yang ada melakukan olahraga. Hasil penelitian menunjukkan bahwa sebagian besar $(62,8 \%)$ responden tidak ada melakukan olahraga di Wilayah Kerja Puskesmas Nanggalo Padang tahun 2015.

Penelitian ini didukung oleh hasil penelitian yang dilakukan oleh Frankillawati (2014) tentang hubungan antara pola makan dan kebiasaan olahraga, dengan kejadian diabetes mellitus di wilayah kerja Puskesmas Nusukan Surakarta. Didapatkan hasil 85\% responden kurang berolahraga. Penelitian ini diperkuat oleh penelitian yang dilakukan oleh Ahmad Eko (2010) di RSUD Prof. Dr. Margono Soekardjo, menemukan bahwa 67\% responden yagn menderita diabates mellitus tidak berolahraga.

Pentingnya gaya hidup kurang gerak sebagai faktor resiko untuk menderita diabetes mellitus dan efek protektif aktifitas fisik sudah banyak diteliti. Kebiasaan olahraga/aktivitas fisik dapat meningkatkan pembuangan glukosa yang diransang insulin pada dosis insulin yang di tetapkan. Selain itu orang yang mengalami penigkatan yang lebih kecil dalam konsentrasi insulin plasma sebagai sebagai respon terhadap beban glukosa dibandingkan dengan orang yang memiliki gaya hidup sedentari/kurang gerak. Hal ini menunjukkan bahwa olahraga dapat meningkatkan sensitivitas jaringan terhadap insulin (Bazzano, 2005). Kebanyakan Lansia mengatakan malas berolahraga lansia lebih memilih duduk-duduk di depan rumah daripada mengikuti senam yang dilakukan oleh kader kesehatan. Lansia tidak mengetahui kalau dengan jarang berolahraga akan memicu salah satu penyakit seperti diabetes mellitus. Olahraga sangat penting dilakukan oleh lansia karena dengan berolahraga dapat membakar kalori dan meningkatkan kekebalan pada tubuh pada lansia. diharapkan kepada lansia agar lebih meningkatkan lagi keinginannya untuk meningkatkan pola hidup sehat dengan berolahraga dan tenaga kesehatan untuk memotivasi lagi lansia untuk mengikuti senam lansia yang dilakukan di Posyandu Lansia RW $1 \mathrm{X}$ dan X Kelurahan Surau Gadang.

\section{Obesitas Pada Lansia di Posyandu Lansia}

Berdasarkan hasil penelitian didapatkan 27 lansia yang mengalami obesitas dan 51 lansia yang tidak mengalami obesitas. Hasil penelitian menunjukkan bahwa bahwa sebagian besar $(65,4 \%)$ responden tidak mengalami obesitas di Wilayah Kerja Puskesmas Nanggalo Padang tahun 2015.

Hasil penelitian ini didukung oleh hasil penelitian yang dilakukan oleh Suarnita (2012) menemukan lebih dari separoh $(58,9 \%)$ responden yang mengalami diabetes mellitus mengalami obesitas. Hasil Penelitian ini bertolak belakang dengan hasil penelitian yang dilakukan oleh Anugrah (2013) di rumah sakit Dr. Wahidin Sudirohusodo Makasar $(62,8 \%)$ sebagian besar responden tidak mengalami obesitas.

Obesitas merupakan faktor resiko utama untuk terjadinya diabetes mellitus. 
Hubungannya dengan diabetes mellitus tipe 2 sangat kompleks sekalipun masih berada di dalam kisaran berat badan yang dapat diterima, namun kenaikan berat badan dapat meningkatkan resiko diabetes mellitus, khususnya jika ada faktor predisposisi familial, diantara faktor-faktor lingkungan, obesitas memiliki korelasi yang paling kuat. Resiko terjadinya diabetes mellitus seiring dengan Indeks Massa Tubuh (IMT) meningkat (Erniati, 2012).

Menurut analisa peneliti sebagian kecil lansia di posyandu lansia RW $1 \mathrm{X}$ dan $\mathrm{X}$ yang mengalami Obesitas. pada saat dilakukan wawancara kepada lansia, lansia mengatakan mengalami obesitas disebabkan karena faktor pola makan yang tidak sehat dan juga ada sebagian lansia mengatakan mengalami obesitas karena dari kecil sudah mengalami obesitas juga. Obesitas pada lansia disebabkan karena rendahnya pengetahuan lansia tentang pola hidup sehat lansia tidak mengetahui kalau dengan makan yang tidak teratur suka makanmakanan yang siap saji akan memicu salah satu penyakit degenerative seperti diabetes mellitus.

\section{Hubungan Jenis Kelamin dengan Kejadian Diabetes Mellitus pada Lansia}

Berdasarkan hasil penelitian didapatkan bahwa kejadian diabetes lebih banyak terjadi pada lansia yang memeliki jenis kelamin perempuan $(80,4 \%)$ dibandingkan dengan jenis kelamin laki-laki (25,0\%). Hasil uji statistik menunjukkan nilai $\mathrm{p}$ value 0,000 $(p<0,05)$ berarti terdapat hubungan jenis kelamin dengan kejadian diabetes mellitus pada lansia di Posyandu Lansia RW IX dan RW X Kelurahan Surau Gadang di wilayah Kerja puskesmas Nanggalo Padang Tahun 2015. Dilihat dari nilai RR didapatkan sebesar 0,311 yang berarti jenis kelamin laki-laki memiliki peluang 0,311 kali lebih besar terjadinya diabetes mellitus dibandingkan yang memiliki jenis kelamin perempuan.

Penelitian ini didukung oleh penelitian yang dilakukan oleh Menurut Nuryah (2010) tentang hubungan karakteristik dengan kejadian diabetes mellitus, menemukan bahwa kejadian diabetes lebih banyak terjadi pada lansia yang memiliki jenis kelamin perempuan $(70,2 \%)$ dibandingkan dengan jenis kelamin laki-laki $(35,2 \%)$. Hasil penelitian ini berbeda dengan hasil penelitian yang dilakukan oleh
Nengsih (2012), menemukan bahwa kejadian diabetes lebih banyak terjadi pada lansia yang memiliki jenis kelamin laki-laki (70,2\%) dibandingkan dengan jenis kelamin perempuan $(45,2 \%)$.

Berdasarkan analisis antara jenis kelamin dengan kejadian DM, prevalensi kejadian DM pada wanita lebih tinggi daripada laki-laki. Wanita lebih berisiko mengidap diabetes karena secara fisik wanita memiliki peluang peningkatan indeks masa tubuh yang lebih besar. Sindroma siklus bulanan (premenstrual syndrome), pasca-menopouse yang membuat distribusi lemak tubuh menjadi mudah terakumulasi akibat proses hormonal tersebut sehingga wanita berisiko menderita diabetes mellitus (Irawan, 2010).

Menurut analisa peneliti salah satu faktor penyebab diabetes mellitus adalah jenis kelamin. Berdasarkan penelitian yang dilakukan, mayoritas kejadian diabetes mellitus pada lansia yang mempunyai jenis kelamin perempuan dibandingkan laki-laki. Pada saat melakukan wawancara banyak ditemukan lansia perempuan yang tidak bekerja dibandingkan dengan lansia yang bekerja, lansia lebih memilih duduk-duduk dirumah daripada melakukan aktivitas fisik atau bekerja. Hal ini terlihat pada saat mlakukan wawancara kebanyakan lansia yang tidak bekerja dibandingkan lansia yang bekerja, sebagian lansia juga ada yang memang sudah pensiun. bisa juga dilihat dari pola hidup perempuan yang tidak sehat dibandingkan laki-laki juga terdapat perbedaan dalam melakukan aktivitas dan gaya hidup sehari-hari yang sangat mempengaruhi kejadian pada penyakit diabetes mellitus. Lansia tidak mengetahui dengan dengan jarang beraktivitas dapat memicu penyakit diabetes mellitus.

Diharapkan agar lansia yang mengalami diabetes mellitus lebih memperhatikn lagi pentingnya melakukan aktivitas fisik dan menjaga pola hidup yang sehat dengan bekerja dan juga makan yang teratur agar terhindar dari penyakit diabetes mellitus, tenaga kesehatan juga dapat memberika informasi kepada lansia akan pentingnya pola hidup yang sehat. 


\section{Hubungan Olahraga dengan Kejadian Diabetes Mellitus pada Lansia}

Berdasarkan hasil penelitian didapatkan bahwa kejadian diabetes mellitus lebih banyak terjadi pada lansia yang tidak ada melakukan olahraga $(83,7 \%)$ dibandingkan dengan yang ada melakukan olahraga $(13,8 \%)$. Hasil uji statistik menunjukkan nilai $\mathrm{p}$ value 0,000 $(\mathrm{p}<0,05)$ berarti terdapat hubungan olahraga dengan kejadian diabetes mellitus pada lansia di Posyandu Lansia RW IX dan RW X Kelurahan Surau Gadang di wilayah Kerja puskesmas Nanggalo Padang Tahun 2015. Dilihat dari nilai RR didapatkan sebesar 6.066 yang berarti yang tidak olahraga memiliki peluang 6.066 kali lebih besar terjadinya diabetes mellitus dibandingkan yang melakukan olahraga.

Hasil penelitian ini didukung oleh penelitian yang dilakukan oleh Riskasari (2013) tentang hubungan kebiasaan olahraga, dengan kejadian diabetes mellitus, menemukan bahwa kejadian diabetes lebih banyak terjadi pada lansia yang tidak ada melakukan olahraga $(63,8 \%)$ dibandingkan dengan yang ada melakukan olahraga $(23,2 \%)$. Menurut Tandra (2008) olahraga pada lansia sangat terbatas apalagi bila ada gangguan pada jantung, sendi, mata, saraf, atau pembuluh darah kaki, lansia yang menderita diabetes mellitus sulit melakukan gerak badan. Namun karena melakukan aktivitas fisik sangat penting dilakukan pada lansia yang menderita diabetes mellitus, pada lansia di anjurkan senam ringan secara perlahan-lahan, sekedar jalan kaki santai, atau sekedar melakukan gerakan tangan dan kaki sambil duduk atau berebahan bila lansia tidak bisa bangun.

Menurut analisa peneliti salah satu faktor penyebab diabetes mellitus adalah kurangnya aktivitas fisik pada lansia. Mayoritas kejadian diabetes mellitus pada lansia yang tidak ada melakukan olahraga dibandingkan yang melakukan olahraga. Lansia tidak melakukan olahraga disebabkan dari lansianya sendiri yang malas melakukan aktivitasfisik seperti senam lansia dan jalan kaki santai, lansia lebih memilih duduk-duduk di rumah dibandingkan melakukan olahraga.

Hal ini terlihat dari kebanyakan lansia memilih untuk tidur-tiduran di rumah serta menonton televisi dibandingkan keluar rumah untuk melakuakan aktivitas olahraga serta dapat juga dilihat dari hasil wawancara kebanyakan lansia banyak yang tidak bekerja daripada yang bekerja. Dengan jarangnya berolahraga akan menyebabkan mudah terkena dibetes mellitus karena olahraga berfungsi membakar kalori yang berlebihan dalam tubuh. Kalori yang tertimbun dalam tubuh merupakar faktor utama penyebab diabetes mellitus.

Diharapkan kepada lansia untuk meningkatkan kemauan dan motivasi untuk melakukan aktivitas fisik karena dengan berolahraga dapat meningkatkan kepekaan insulin, mencegah kegemukan, dapat membakar kalori dalam tubuh, meningkatkan kekuatan otot jantung serta memperkecil resiko terjadinya serangan jantung. dan kepada tenaga kesehatan dapat memberikan motivasi lagi kepada lansia untuk meningkatkan pola hidup sehat dan mau melakukan kegiatan olahraga seperti senam agar terhindar dari penyakit diabetes mellitus.

\section{Hubungan Obesitas dengan Kejadian Diabetes Mellitus pada Lansia}

Berdasarkan hasil penelitian didapatkan bahwa kejadian diabetes lebih banyak terjadi pada lansia yang mengalami obesitas $(88,9 \%)$ dibandingkan dengan yang tidak mengalami obesitas (41,2\%). Hasil uji statistik menunjukkan nilai $\mathrm{p}$ value $0,000 \quad(\mathrm{p}<0,05)$ berarti terdapat hubungan obesitas dengan kejadian diabetes mellitus pada lansia di Posyandu Lansia RW IX dan RW X Kelurahan Surau Gadang di wilayah Kerja puskesmas Nanggalo Padang Tahun 2015. Dilihat dari nilai RR didapatkan sebesar 2.159 yang berarti yang obesitas memiliki peluang 2.159 kali lebih besar terjadinya diabetes mellitus dibandingkan yang tidak obesitas.

Penelitian ini didukung oleh penelitian yang dilakukan oleh Kurniasari (2010), menemukan bahwa kejadian diabetes lebih banyak terjadi pada lansia yang mengalami obesitas $(78,1 \%)$ dibandingkan dengan yang tidak mengalami obesitas $(31,9 \%)$. Sedangkan penelitian yang berbeda dilakukan Lisma Anggraini (2013) menemukan bahwa kejadian diabetes lebih banyak terjadi pada lansia yang mengalami obesitas $(78,3 \%)$ dibandingkan dengan yang tidak mengalami obesitas $(31,7 \%)$.

Obesitas merupakan faktor resiko utama untuk terjadinya diabetes mellitus. Hubungannya dengan diabetes mellitus tipe 2 sangat kompleks sekalipun masih berada di 
dalam kisaran berat badan yang dapat diterima, namun kenaikan berat badan dapat meningkatkan resiko diabetes mellitus, khususnya jika ada faktor predisposisi familial, diantara faktor-faktor lingkungan, obesitas memiliki korelasi yang paling kuat. Resiko terjadinya diabetes mellitus seiring dengan Indeks Massa Tubuh (IMT) meningkat dan keadaan ini menunjukkan korelasi dose responce antara lemak tubuh dan dan resistensi insulin. Faktor yang mempengaruhi resistensi insulin pada obesitas meliputi kadar asam lemak yang tinggi dalam darah yang beredar dalam intrasel (Erniati, 2012).

Menurut analisa peneliti obesitas sangat mempengaruhi terjadinya diabetes mellitus. Dalam penelitian ini terdapat banyak lansia yang mengalami obesitas dari pada lansia yang mengalami diabetes mellitus yang tidak ada obesitas. Pada saat melakukan wawancara beberapa orang lansia mengatakan mengalami obesitas karena sejak kecil sudah mengalami obesitas juga, dan sebagian lansia mengatakan mengalami obesitas disebabkan faktor lingkungan seperti gaya hidup lansia yang tidak sehat dan pola makan yang tidak teratur dan suka makan pada malam hari serta kurangnya berolahraga pada lansia. Lansia tidak mengetahui kalau dengan obesitas dapat menyebabkan diabetes mellitus, karena dengan makan yang berlebihan akan menyebabkan banyak lemak dalam tubuh sehingga insulin tidak adapat bekerja dengan baik pada pankreas dan juga dari faktor genetik seseorang lansia yang mengalami obesitas disebabkan karena faktor genetik juga bisa terjadi diabetes mellitus jika ada salah satu anggota keluarganya yang menderita diabetes mellitus juga.

\section{KESIMPULAN DAN SARAN}

Hasil penelitian menunjukkan bahwa $(57,7 \%)$ lansia mengalami diabetes mellitus, $(52,6 \%)$, jenis kelamin perempuan, $(62,8 \%)$ tidak ada olahraga, dan $(65,4 \%)$ tidak obesitas. Uji Chi-Square disimpulkan terdapat hubungan yang signifikan antara faktor jenis kelamin $(\mathrm{p}=0,000)$ olahraga $(\mathrm{p}=0,000)$ dan obesitas $(\mathrm{p}=0,000)$ dengan kejadian diabetes mellitus. Pencegahan diabetes mellitus dapat dilakukan dengan meningkatkan pengetahuan lansia dengan memberikan penyuluhan dan memperbaiki pola makan

\section{DAFTAR PUSTAKA}

Ahmad Eko. 2010. Hubungan Kebiasan Olahraga dengan Kejadian Diabetes Mellitus di RSUD Prof. Dr. Margono Soekardjo. Skripsi. www.respitory.com, diakses tanggal 26 Juli 2015

Almatsier, Sunita. 2007. Penuntun Diet. Jakarta: Gramedia Pustaka Utama

Badawi. 2009. Melawan dan Mencegah Diabetes Melitus . Yogyakarta

Bazzano LA. 2005. Preventionn Of Type 2 Diabetes by Diet and Lifestyle Modification. J. Am. Coll. Nutr

Bustan, M. N. 2007. Epidemiologi Penyakit Tidak Menular. Jakarta: Rineka Cipta.

Debbi, Anggraini. 2010. Hubungan Faktor Genetik dengan Kejadian Diabetes Mellitus di Wilayah Kerja Puskesmas Sidomulyo. www.jurnalkesehatan.com, diakses tanggal 3 Agustus 2015.

Hasdianah. 2012. Mengenal Diabetes Mellitus pada Orang Dewasa dan Anak-Anak dengan Solusi Herbal. Yogyakarta: Nuha medika.

Hidayat, A. 2009. Metode Penelitian Keperawatan dan Teknik Analisis Data. Jakarta: Salemba Medika

Kurniawan. 2011. Gambaran Kejadian Diabetes Mellitus pada Lanjut Usia di Puskesmas Wawonasa. www.jurnalkesehatan.com, diakses tanggal 2 Juli 2015.

Lisma Anggraini. 2013. Hubungan Obesitas dengan Kejadian Diabetes Mellitus di Kecemasan Brebes. www.jurnalkesehatan.com, Diakses tanggal 3 Juli 2015.

Manganti, Alisa. 2012. Panduan Hidup Sehat dengan Diabetes. Yogyakarta : Araska.

Mansjoer. 2010. Kapita Selecta Kedokteran Jilid 1 Edisi Ketiga. Jakarta: Media Aesculapius.

Martini. 2011. Hubungan Faktor Genetik dengan Kejadian Diabetes Mellitus pada Lansia di Kelurahan Singkil. . www.jurnalkesehatan.com, Diakses tanggal 2 Juli 2015.

Mendrayani. 2009. Hubungan Olahraga dengan Kejadian Diabetes Mellitus di Kelurahan Ketang Baru. 
www.mediakesehatan.com, Diakses tanggal 12 Agustus 2015.

Nengsih. 2012. Hubungan antara Jenis Kelamin dengan Kejadian Diabetes Mellitus di Wilayah Kerja Puskesmas Wawonasa. www.mediakesehatan.com, diakses tanggal 8 Agustus 2015.

Nugroho. 2011. Asuhan Keperawatan Maternitas, Bedah, dan Penyakit Dalam. Yogyakarta: Nuha Medika.

Nursalam. 2013. Metodologi Penelitian Ilmu Keperawatan , Pendekatan Praktis, Edisi 3. Jakarta: Salemba Medika.

Nuryah. 2010. Hubungan Karakteristik dengan Kejadian Diabetes Mellitus di Kecamatan Singkil. www.mediacastro.com, diakses tanggal 18 Juli 2015.

Rinaldo. 2009. Hubungan Aktifitas Fisik dengan Kejadian Diabetes Mellitus di Rumah Sakit Dr. Kariadi Semarang. www.jurnalkesehatan.com, Diakses tanggal 30 Juli 2015.

Riset Kesehatan Dasar. 2013. Pervalensi Penyakit Diabetes Mellitus. Padang.

Riskasari. 2013. Hubungan Kebiasaan Olahraga, dengan Kejadian Diabetes Mellitus di Rumah Sakit Roemani Semarang. www.jurnalkesehatan.com, Diakses tanggal 12 Juli 2015.

Rosyada. 2013. Determinan Komplikasi Kronik Diabetes Mellitus Pada Lanjut Usia di RSUD Rantauprapat Kabupaten Labuhanbatu.

www.jurnalkesehatan.com, Diakses tanggal 30 Juli 2015.

Sari Retno Novita. 2012. Diabetes Mellitus. Yogyakarta: Nuha medika.

Soegondo. 2010. Buku Panduan Penatalaksanaan Diabetes Mellitus di Layanan Kesehatan Primer di Indonesia. Departemen Ilmu Kedokteran Komunitas. Jakarta. FKUI.

Soewondo. 2006. Hidup sehat bebas diabetes. Yogyakarta : Araska

Suarnita. 2012. Faktor yang Berhubungan dengan Kejadian Diabetes Mellitus di RSUD Banyumas. www.respitory.com, diakses tanggal 26 Juli 2015.

Suiraoka, 2012. Penyakit Degeneratif. Yogyakarta : Nuhamedika

Sudoyo, Aru W. (2007). Buku Ajar Ilmu Penyakit Dalam. Jakarta: Pusat Penerbitan Departemen Penyakit Dalam
Fakultas Kedokteran Universitas Indonesia.

Syamsiah. 2014. Faktor Resiko Kejadian Diabetes Mellitus Tipe 2 pada Wanita di Puskesmas Kelurahan Pasangrahan Jakarta Selatan Tahun 2014. http://Skripsi.Universitas.Negeri.Syarif. Hidayatullah.Jakarta.ac.id. Diakses pada tanggal 05 Juni 2015.

Utami, Dkk. 2013. Faktor-Faktor Yang Mempengaruhi Kualitas Hidup Pasien Diabetes Mellitus dengan Ulkus Diabetikum di RSUD Arifin Achmad Provinsi Riau. www.Jurnal.Universitas.Riau.ac.id.Diak ses pada 26 Februari 2015.

Wahyuni. 2014. Faktor-Faktor yang Berhubungan dengan Penyakit Diabetes Mellitus Didaerah Perkotaan di Indones ia. http//skripsi.universitas.islam.syarif. hidayatullah.Jakarta.ac.id.diakses pada 05 juni 2015.

Wulandari, 2013. Faktor yang Mempengaruhi Kejadian Diabetes Melitus di POLWIL Samarinda. Skripsi. www.blogspot.com, Diakses tanggal 14 Juli 2015

Yunir dan Soebardi. 2008. Buku Ajar Ilmu Penyakit Dalam. Jakarta. FKUI

Yuliani. 2014. Hubungan Berbagai Faktor Risiko Terhadap Kejadian Diabetes Mellitus di Wilayah Kerja Puskesmas Tanjung Jabung. http.skripsi.ac.id. Diakses 06 Agustus 2015

Zarni. 2010. Hubungan Karakteristik Responden dengan Kejadian Diabetes Mellitus di Wilayah Kerja Puskesmas Sungai Aur. Skripsi. www.repositoryunand.com, Diakses tanggal 5 Agustus 2015. 